\title{
CARACTERÍSTICAS TIMBRÍSTICAS ENTRE GUITARRAS ELÉTRICAS DE CORPOS SÓLIDOS E SEMI-SÓLIDOS
}

\author{
Alexsander Vanzela, licenciado em Música com habilitação em Guitarra pela UNINCOR em Três Corações/MG \\ (2011), pós-graduado em Educação Musical pela Universidade Cândido Mendes UCAM - Prominas (2012), atualmente \\ é professor de guitarra elétrica no Conservatório Estadual de Música “Lobo de Mesquita” em Diamantina-MG. \\ www.alexvanzela.com \\ email: alexvanzela@gmail.com
}

Leandro Mesquita Trombini, licenciado em Música com habilitação em Guitarra pela UNINCOR em Três Corações/MG (2011), Leciona guitarra em Juiz de Fora - MG.

Email: leandro.ae@gmail.com

Trabalho de Conclusão de Curso para obtenção do grau de licenciado em Música, aprovado pela Universidade Vale do Rio Verde - UNINCOR em 3 de Dezembro de 2011, orientado pelo professor Endre Solti.

\section{Recebido em: 30/10/2013 - Aprovado em: 20/12/2013 - Disponibilizado em: 15/01/2014}

\begin{abstract}
RESUMO
A guitarra elétrica, em suas versões pioneiras, apresentou duas vertentes, sendo uma de corpo sólido devido ao sustain e a outra de corpo semi-sólido por seu timbre mais encorpado. Nas últimas décadas, a popularização deste instrumento levou ao desenvolvimento de variados modelos, que entretanto, em sua maioria são produzidos com madeiras nobres. $\mathrm{O}$ presente trabalho teve por objetivo o desenvolvimento de uma guitarra elétrica de corpo semi-sólido com características de guitarra com corpo sólido, visando obter um instrumento que fosse ao mesmo tempo adequado para a execução de vários estilos musicais e produzido com madeira nacional com menor impacto sobre o custo de fabricação. Na construção foram utilizadas as madeiras Pau Pereiro (tampo, braço e headstock); Braúna (escala) e Cedro (corpo). Para avaliar a aceitação do modelo AV-1 produzido foram realizadas pesquisas de opinião com estudantes do curso de música da Universidade Vale do Rio Verde e outras. A avaliação timbrística foi realizada em estúdio utilizando-se o programa PAZ Analyzer, um plugin do ProTools no computador Imac. Os resultados obtidos mostraram que a guitarra modelo AV-1 teve boa aceitação, sendo que 89\% consideraram seu visual entre "lindo" e "bonito"; $98 \%$ avaliaram os captadores entre "ótimo" e "bom"; 79\% avaliaram a ponte e a alavanca como "bom" e "ótimo". Nos testes de avaliação timbrística, o modelo AV-1 apresentou bons desempenhos. Desta forma, é possível concluir que a utilização de madeiras nacionais poderá permitir a fabricação de guitarras elétricas com custo mais acessível e qualidade semelhante à das melhores marcas do mercado.
\end{abstract}

Palavra Chave: Guitarra Elétrica, Construção de guitarra, corpo semi-sólido, Pau Pereiro, Braúna. 


\begin{abstract}
The electric guitar in his pioneering versions, presented two strands, one solid body due to sustain and other semi solid body for her fatter tone. In recent decades, the popularity of this instrument led to the development of various models, however, are mostly produced with hardwoods. This work aimed at the development of an electric guitar semi - solid body guitar features with solid body, to obtain an instrument that is at the same time suitable for the implementation of various musical styles and produced from domestic timber with less impact on the cost of manufacturing. Braunstone ( scale) and Cedar ( body) ; building in the woods Pau Pereiro ( top , arm and headstock ) were used . To evaluate the acceptance of the AV - 1 model produced surveys with students of Music University of Vale do Rio Verde and others were performed. The timbre evaluation was performed in the studio using the PAZ Analyzer program a plugin in ProTools Imac computer. The results showed that the AV - 1 model guitar was well received, with $89 \%$ considered their visual between " gorgeous " and " beautiful ", 98\% rated the pickups between " great" and " good" , 79\% rated the bridge and lever as " good" and " great." Timbre of the evaluation tests , the AV - 1 model showed good performances. Thus, we conclude that the use of domestic wood may allow the manufacture of electric guitars more affordable and similar to that of the best quality brands in the market
\end{abstract}

Keyword: Electric Guitar, guitar construction, solid body, Pau Pereiro, Braúna. 


\section{INTRODUÇÃO}

No final da década de 40 e em meados da década de 1950, sob a influência de nomes como Adolph Rickenbacker, Les Paul e Leo Fender, iniciou-se a fabricação da guitarra elétrica maciça, pois até então apenas a guitarra acústica, popularmente conhecida como violão aqui no Brasil, estava adequada à utilização musical (SOUZA, 2002). Com a necessidade de um instrumento com a capacidade de se amplificar o som sem uma realimentação ou "feedback", houve uma adequação do instrumento que, ao invés de ter seu corpo totalmente oco internamente, assim como a caixa de ressonância do violão, madeiras sólidas passaram a ser utilizadas, com ou sem a necessidade de um tampo, fundo ou qualquer outro material. Deste modo, apenas a madeira, as cordas e os captadores eram responsáveis pela emissão do som. Além disso, a ponte e todo o sistema elétrico também passaram a fazer parte da produção timbrística do instrumento. No entanto, a compreensão de som é reconhecida por utilizar apenas estes três elementos: madeira, encordoamento e captadores.

Apesar de muitos guitarristas hoje em dia preferirem as guitarras de corpo maciço, existem aqueles que adotam as guitarras semiacústicas para suas performances, principalmente nos estilos musicais de MPB e Jazz.

Com o aparecimento de várias tecnologias da engenharia da música, que contribuíram para o aperfeiçoamento das guitarras elétricas, juntamente com a utilização de matérias primas diferenciadas, tais como a fibra de carbono e o vidro (ONO \& OKUDA, 2007), a madeira deixou de ser a única opção de matéria-prima, apesar de sua textura e colorido sonoro que produz ser ainda o principal material utilizado pelos luthiers.

O objetivo deste trabalho foi viabilizar um instrumento híbrido, ou seja, uma guitarra que poderá servir a uma grande extensão de estilos musicais, procurando obter certa peculiaridade sonora. Assim foi realizado um estudo para a obtenção de um produto com características que atendam as principais necessidades de cada estilo musical, sem deixar de lado a parte estética do instrumento e a facilidade de utilização do braço, alavanca e chave seletora.

Para isso, foi construída a guitarra modelo AV-1, com características que se acharam necessárias para atender tais objetivos. E, de modo a provar sua eficiência como instrumento, a guitarra foi testada, tanto por guitarristas quanto através de programas de áudio, de modo a avaliar seu desempenho e características sonoras, bem como a comparálo com o de outros modelos clássicos de guitarras.

A idealização do instrumento em questão se deu a partir de nossas experiências no mundo musical, utilizando e regulando guitarras, a partir de opiniões de vários guitarristas sobre os seus interesses do que 
gostariam de aperfeiçoar em seus instrumentos e ao final, identificamos alguns componentes que fazem falta ou que seriam importantes para uma melhor performance musical.

\section{CRIAÇÃO DO INSTRUMENTO}

A construção de uma guitarra perfeita é utópica, pois esta teria que unir muitos componentes em um só instrumento. Além disso, existe o fator individual de cada músico. Decidimos então que, no presente trabalho, a guitarra seria semi-acústica, porém com o corpo de proporções de uma guitarra de corpo sólido, para tentarmos alcançar um som e um visual que satisfizesse o gosto da maioria dos guitarristas.

A partir disso, foi decidido o tipo de ponte que seria utilizada, se esta seria fixa ou móvel. Como o instrumento que estávamos desenvolvendo deveria satisfazer uma grande variedade de estilos, de acordo com cada guitarrista, resolvemos que a ponte deveria desempenhar esse papel, por isso, optamos em utilizar uma ponte que é fixada ao corpo do instrumento, mas também possui microafinação e uma alavanca. Desse modo, o guitarrista ao utilizar o instrumento poderá optar pela alavanca ou não, tendo em vista que isso não afetará seu desempenho. Ao contrário, o desempenho poderá ser ainda melhor porque a afinação não se perderá visto que a guitarra tem uma trava na pestana e, com a ponte móvel, os bends poderiam ficar mais macios e mais agradáveis de serem executados ao passo que com uma ponte fixa os bends poderiam ficar mais pesados.

Os timbres, produzidos através de captadores, são, normalmente, a característica mais marcante e mais almejada pelos guitarristas. Esses "senhores" do som fazem com que os guitarristas fiquem quase loucos por causa do timbre. Alguns guitarristas preferem o timbre gordo e macio de um humbucker, outros têm em sua preferência os singles que tem um som mais cortante e agudo. Na guitarra AV-1 será utilizada a configuração de dois captadores humbuker distortion.

Para que a performance timbrística fosse semelhante à das guitarras que servirão de comparação, resolvemos utilizar uma chave de três posições. Contudo, essa característica poderá ser modificada, caso seja necessário no futuro, adequando-se os captadores para a utilização de uma chave de cinco posições, onde possivelmente poderemos estar cancelando a fase de cada bobina, tendo assim cinco ou mais possibilidades de timbres distintos.

Para $o$ teste de freqüência foram avaliados os níveis dos captadores, utilizando nesta fase uma guitarra modelo Ibanez AS73 semi-acústica, com dois humbuckers e ponte fixa, uma guitarra Gibson Les Paul Standard carved top semi-sólida possuindo também dois humbuckers e ponte fixa, uma guitarra modelo Jackson KV1 com ponte fixa e uma guitarra modelo Ibanez Roadstar com ponte 
flutuante Floyd Rose, sendo as duas últimas de corpo sólido e com dois captadores humbuckers. As especificações de cada modelo estão apresentadas na Tabela 1 .

\begin{tabular}{|c|c|c|c|c|}
\hline Guitarra & $\begin{array}{c}\text { Madeira } \\
\text { Braço }\end{array}$ & $\begin{array}{c}\text { Madeira } \\
\text { Corpo }\end{array}$ & $\begin{array}{c}\text { Madeira } \\
\text { Escala }\end{array}$ & Captador \\
\hline $\begin{array}{l}\text { Gibson Les } \\
\text { Paul } \\
\text { Standard } \\
\text { carved top }\end{array}$ & Mogno & $\begin{array}{c}\text { Maple } \\
\text { (superior) e } \\
\text { Mogno } \\
\text { (inferior) }\end{array}$ & Rosewood & $\begin{array}{c}\text { Burstbucker } \\
\text { Pro }\end{array}$ \\
\hline $\begin{array}{l}\text { Ibanez } \\
\text { Semi- } \\
\text { acústica } \\
\text { AS73 }\end{array}$ & Mogno & Maple & $\begin{array}{c}\text { Bound } \\
\text { Rosewood }\end{array}$ & $\begin{array}{l}\text { ACH1 e } \\
\text { ACH2 }\end{array}$ \\
\hline $\begin{array}{c}\text { Jackson } \\
\text { KV1 }\end{array}$ & Maple & Poplar & Ébano & $\begin{array}{c}\text { Seymour } \\
\text { Duncan SH6 } \\
\text { e SH2 }\end{array}$ \\
\hline $\begin{array}{c}\text { Ibanez } \\
\text { Roadstar }\end{array}$ & Maple & Mogno & Rosewood & Low Z \\
\hline
\end{tabular}

Tabela 1 - Características das guitarras utilizadas para a comparação do desempenho da AV-1

Por fim, optamos por utilizar uma escala de 24 trastes, sendo que, a partir do décimo segundo traste existirá o escalope (processo que consiste na retirada de uma parte da madeira da escala para que esta fique mais profunda e não dê atrito entre os dedos e a madeira da escala). Deste modo, pessoas com dedos mais grossos poderão tocar com maior facilidade e destreza, além de facilitar bends e ligados.

A guitarra modelo AV-1 foi fabricada pela luthieria Imagem e Som, dos proprietários Henrique de Oliveira Lima e Paulo Emílio Oliveira Lima, apresentando formas circulares, tampo colado, ponte do tipo flutuante, captadores duplos (humbucker) e travas nas cordas, com centro sólido e laterais escavadas, que soam como uma caixa de ressonância. Como a intenção é o experimentalismo e novas opções de materiais, foram utilizadas madeiras da região. Sem que nos deixássemos de preocupar com a questão ambiental, as espécies escolhidas foram as que podem ser replantadas. Portanto, para o corpo foi utilizado o Cedro (figuras 1a e 1b), para a escala utilizamos a Braúna (figuras 2a e 2b), que é macia e permitiu o escalopamento (figuras 3a e 3b), para o top ou tampo foi utilizado o Pau Pereiro (figuras 4a e 4b), para o braço e o Headstok também foi utilizado o Pau Pereiro (figura 5a e 5b). O Headstok foi laminado com Braúna para dar suavidade e destacar o detalhe da curvatura (figuras $6 \mathrm{a}$ e $6 b)$.

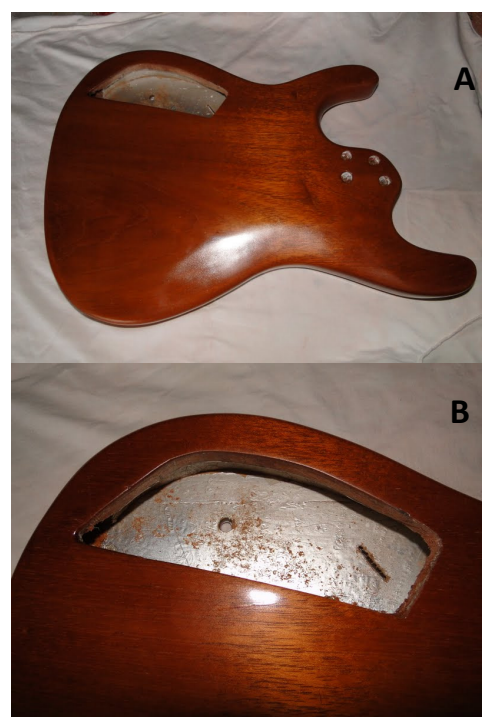

Figuras 1a e 1b - Corpo da guitarra modelo AV-1 feito de madeira tipo Cedro. 

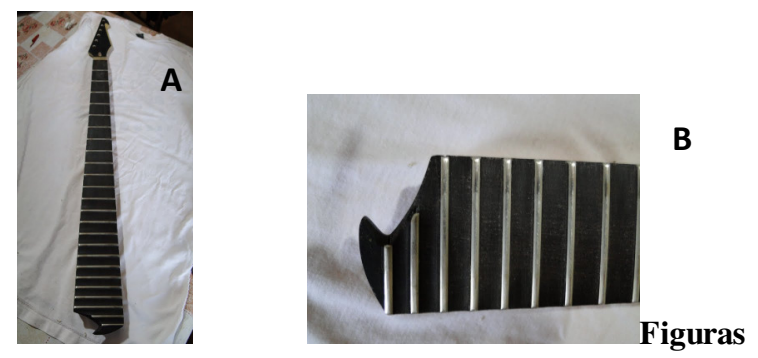

2a e 2b - Escala da guitarra modelo AV-1 feito com madeira tipo Braúna.

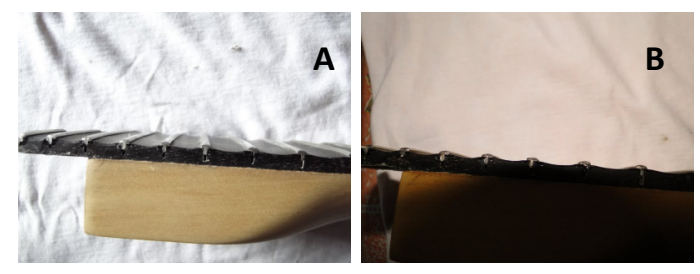

Figuras 3a e 3b - Escalope feito na escala da guitarra AV-1.
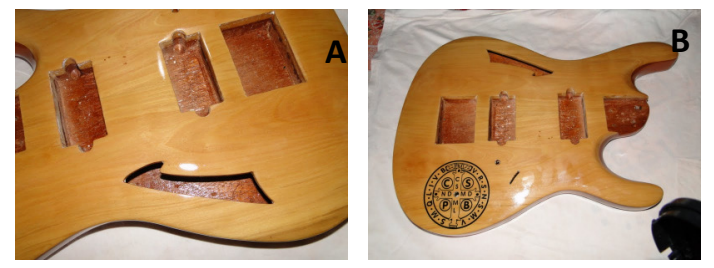

Figuras 4a e 4b - Tampo da guitarra AV-1 em madeira Pau Pereiro
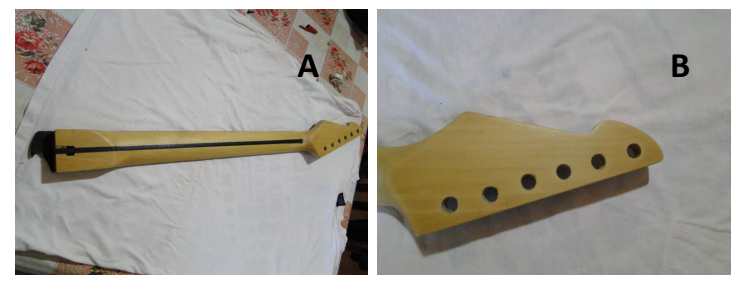

Figura 5 - Braço (a) e Head Stock (b) da guitarra AV1 em madeira Pau Pereiro.
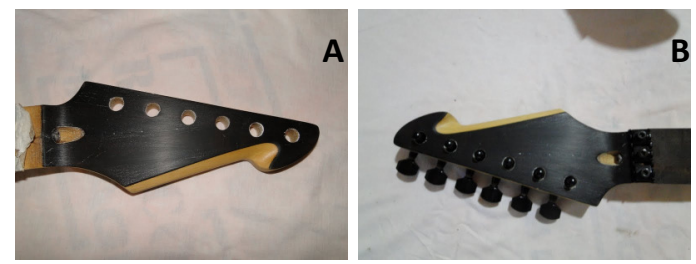

Figuras 6a e 6b - Head Stock da guitarra AV-1 laminado com madeira tipo Braúna.
A ponte utilizada foi do tipo flutuante da marca Sigma (figura 7), que faz com que a guitarra possa ter a afinação sempre intacta e também deixa o guitarrista livre para utilizar ou não a alavanca para subir ou descer tons.

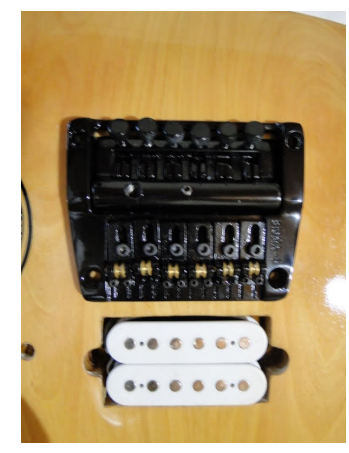

Figura 7 - Ponte flutuante marca Sigma.

Como captadores foram utilizados dois Humbuckers Distortion com imã de Alnico 5 (figuras 8 a e $8 b$ ), que possuem alta saída fazendo com que a sonoridade seja adequada a vários estilos musicais, mas com a presença do defasador estes captadores terão um estilo clássico de guitarras do modelo Stratocaster.

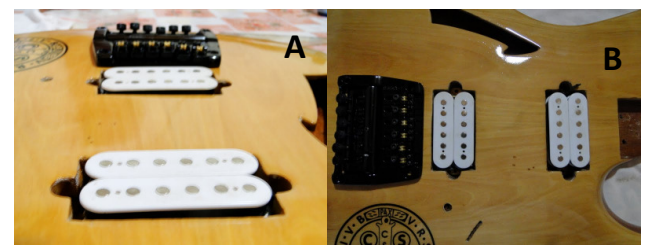

Figuras 8a e 8b - Captadores Humbucker Distortion.

Tarrachas e travas usadas foram da marca Gotoh®. As tarrachas blindadas (figura 9) possibilitam uma excelente ação e as travas (figuras 10a e 10b) por sua vez mantêm a afinação presa através de seus três parafusos. O circuito elétrico provém de dois potenciômetros de 500k (figuras 10b e 11), 
um sendo utilizado para volume e o outro para tonalidade.

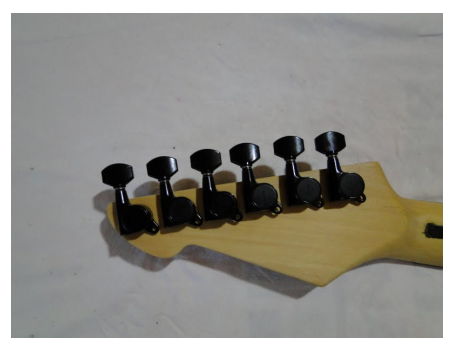

Figura 9 - Tarrachas blindadas da marca Gotoh ${ }^{\circledR}$.
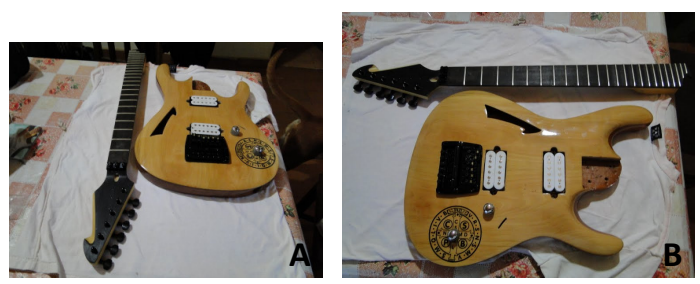

Figuras 10a e 10b - Braço e corpo da guitarra modelo AV-1.

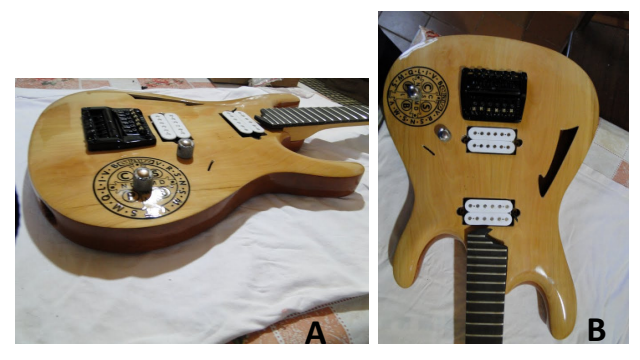

Figuras 12a e 12b - Detalhes da guitarra AV-1.

Para o jack de entrada (figuras 12a) foi instalado um modelo que não é blindado. O acabamento no top foi feito utilizando verniz natural PU (figuras 10b, 11, 12a e 12b), e para os trastes, fizemos uma escala com 24 trastes opacos da marca Vangent (figuras $2 \mathrm{a}$ e $2 \mathrm{~b}$ ). Esta escala terá um pequeno escalope (figuras 3 a e $3 b$ ) dos trastes $12^{\circ}$ até o $24^{\circ}$, para facilitar a mobilidade dos dedos e possibilitar maior velocidade.
Finalmente, para as análises posteriores foi utilizado encordoamento Blue Steel 0,10-0,46 da marca Dean Markley.

\section{PESQUISA DE CAMPO}

A segunda fase dos estudos consistiu em testes realizados por alguns músicos com a guitarra AV-1. O campo de pesquisa foi na própria Unincor, visto que a faculdade de música estava em pleno funcionamento durante o ano letivo. Assim, a guitarra foi disponibilizada para os que desejaram testa-la, juntamente com um amplificador da marca Marshall. A ficha preenchida pelos que testaram a guitarra e se disponibilizaram a preenchê-la está apresentada no anexo A.

Das nove pessoas que preencheram o formulário, todas eram guitarristas, e apenas 3 não eram estudantes da UNINCOR. Apenas um dos entrevistados não gostou do shape da guitarra, devido à cor utilizada, enverrnizamento, textura e polimento da madeira. $67 \%$ dos guitarristas aprovaram o braço do modelo e $33 \%$ desaprovaram por três motivos diferentes: o escalope, a espessura e o tamanho da escala. Um total de oito dentre nove pessoas afirmaram que comprariam o instrumento, se o modelo de guitarra AV-1 estivesse à venda. Os demais resultados obtidos com a pesquisa de opinião estão apresentados nas figuras de 13 a 16 abaixo. 


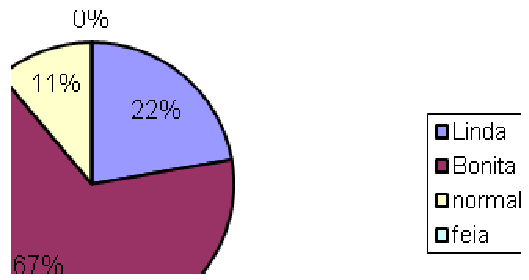

Figura 13 - Opiniões sobre o visual da guitarra AV-1.
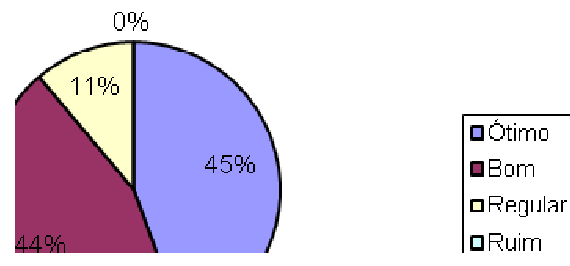

Figura 14 - Opiniões acerca do timbre do captador do braço da guitarra AV-1

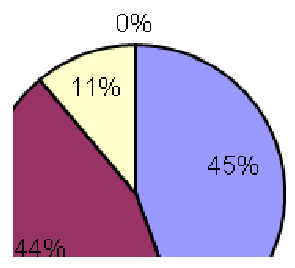

\begin{tabular}{|l}
\hline QÓtimo \\
aRinm \\
QRegulda \\
QRuim
\end{tabular}

Figura 15 - Opiniões acerca do timbre do captador da ponte da guitarra AV-1.
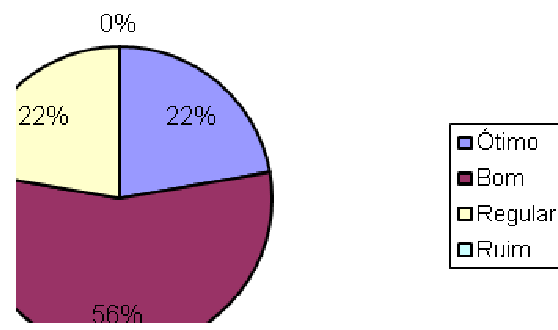

Figura 16 - Opiniões sobre a ponte e a alavanca apresentadas na guitarra AV-1.

\section{TESTE EM ESTÚDIO}

Os testes em estúdio de todos os instrumentos envolvidos neste trabalho ocorreram na cidade de Juiz de Fora. As guitarras foram ligadas e para análise dos resultados foi utilizado o programa PAZ Analyzer, um plugin do ProTools no computador Imac.

As principais características das guitarras utilizadas para as comparações foram apresentadas na Tabela 1 como descrito acima.

De acordo com estes testes, demonstrados nas figuras de 17 a 26 no anexo $B$, pode-se notar que a frequência da nota fundamental foi a mesma em todos os casos testados, pois a nota reproduzida foi idêntica em todos os modelos de guitarras comparados. A única variação que pode ser notada entre uma guitarra e outra foram nos harmônicos, devido às diferenças de composição de um instrumento para outro, tais como madeira, captação, cordas, entre outros elementos estruturais das guitarras.

Em comparação aos outros modelos de guitarras testados, a AV-1 obteve bons resultados, dentro do que era esperado neste trabalho.

De acordo com os resultados de análises sonoras, bem como as opiniões manifestadas pelos instrumentistas que testaram a $\mathrm{AV}-1$, podemos afirmar que as madeiras de origem nacional, utilizadas para a fabricação desta guitarra apresentam uma qualidade 
semelhante à das madeiras utilizadas em guitarras importadas. Resultado semelhante ao alcançado por Fernandes (2004), segundo o qual, as diversas espécies de madeiras nativas do Brasil podem produzir guitarras de qualidade, sendo cada um dos tipos, um indicativo da potencialidade do instrumento.

Assim, em concordância com a proposta deste trabalho, foi possível viabilizar a fabricação de um instrumento com um custo mais baixo e qualidade semelhante ao importado, tendo em vista que madeiras nacionais são, na maioria das vezes, economicamente mais viáveis.

\section{CONCLUSÃO}

Como esse trabalho visou abranger dois universos musicais, a guitarra elétrica sólida e a guitarra elétrica semi-sólida ou semi-acústica, a construção foi feita de forma visceral, visto que foram utilizadas madeiras um pouco fora do comum em relação ao que é utilizado no mercado, por um motivo muito simples: a viabilização de uma construção mais econômica para os padrões brasileiros. $\mathrm{O}$ instrumento construído (guitarra AV-1) ficou visualmente bonito, tendo suas formas bem sutis, confrontando o visual atual com a sonoridade clássica. Seus timbres ficaram adequados aos parâmetros exigidos tanto pelos guitarristas que utilizam guitarras de corpo sólido quanto por aqueles que utilizam guitarras semi-acústicas.
Os resultados da pesquisa de campo foram muito bons, tendo em vista que os músicos que utilizaram a AV-1 acharam que ela apresenta em geral boas características visuais e sonoras, com boa tocabilidade e atendendo a vários guitarristas de diversos estilos musicais.

Do mesmo modo, em estúdio, o instrumento provou ser capaz de atuar como um substituto muito viável aos modelos internacionais com os quais foi comparado. As madeiras nacionais utilizadas neste estudo provaram ser capazes de substituir as tradicionalmente utilizadas em instrumentos importados. Bem se sabe que adequar um instrumento a vários estilos musicais distintos não é uma tarefa fácil, portanto vale salientar que o instrumento foi construído a partir de referências que obtivemos com nossas experiências enquanto guitarristas. Deve-se ressaltar também que novos testes e estudos são fundamentais para a constante melhoria do equipamento aqui apresentado.

Através da análise dos gráficos que avaliaram a potência sonora $(\mathrm{db})$ em função da frequência sonora (htz) dos instrumentos amostrados podemos notar umas diferenças no sustain (o tempo duração da nota), bem como o decay (decaimento do som) das notas reproduzidas. Para explicar este fato podemos recorrer na qualidade de reprodução dos sons na guitarra. Tendo isto em vista, para que se estabeleça a característica responsável pelas diferenças notadas entre as guitarras, deve-se 
realizar mais estudos, que aprofundem a análise estrutural dos instrumentos. Só assim poderemos estabelecer qual componente (se é a madeira, se são os captadores) interfere mais na reprodução sonora de uma guitarra. à constituição de cada guitarra avaliada, de suas madeiras e periféricos. No caso das madeiras, as mais tradicionalmente utilizadas são Maple e Mogno ambas de alta densidade e muito sustain. Já a madeira Poplar é bem mais leve e menos densa. Isto, no entanto não pode ser considerada a única razão para tais diferenças, pois em muitos casos os periféricos utilizados (captadores, principalmente) interferem e muito

\section{Resultado Final AV-1}
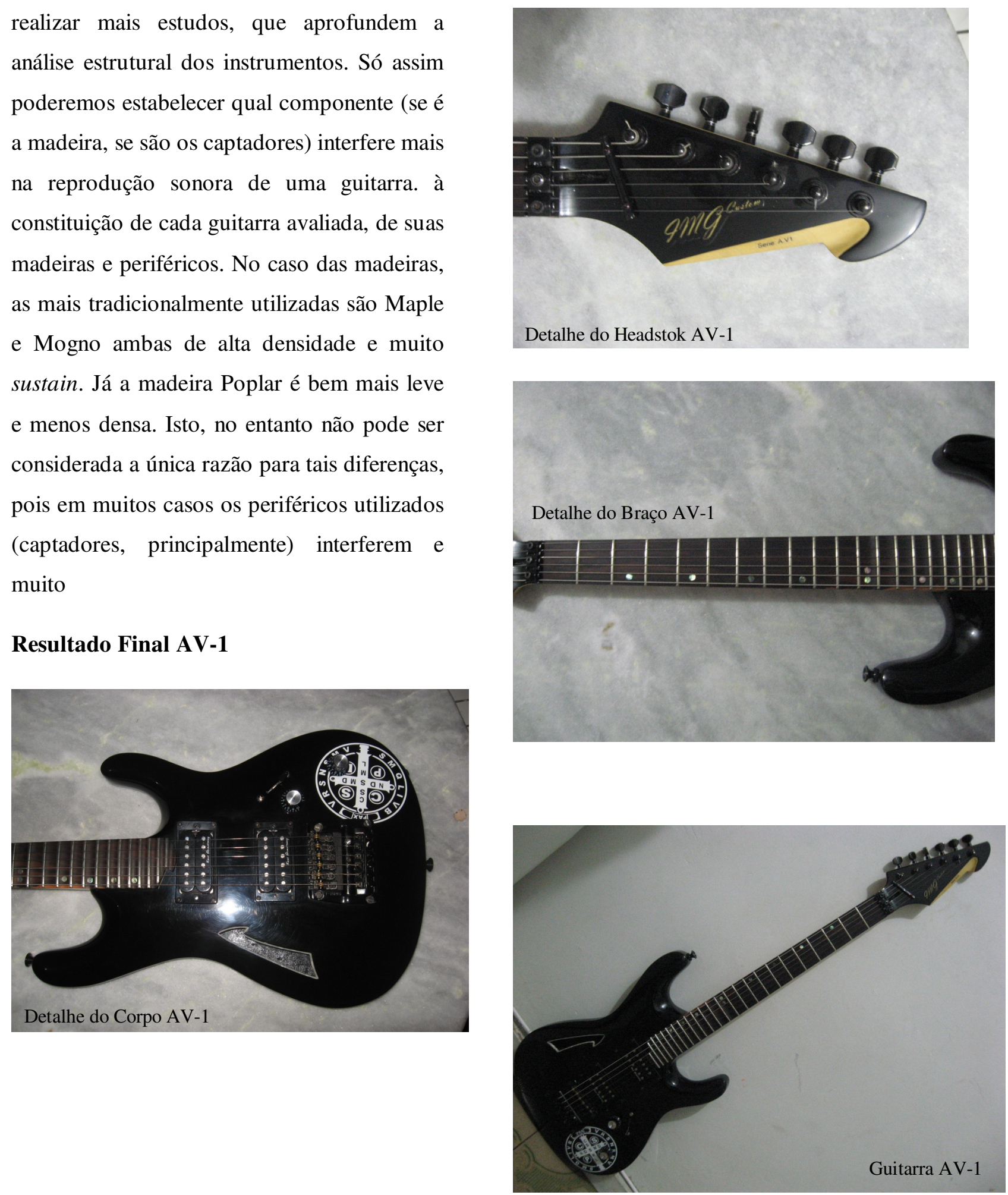


\section{ANEXO A}

Ficha utilizada na pesquisa de opiniões.

Pesquisa realizada em 10 de setembro de 2011

referente ao TCC na Unincor Três Corações/MG

CARACTERISTICAS SONORAS E

TIMBRÍSTICAS ENTRE GUITARRAS

ELÉTRICAS COM CORPOS SÓLIDOS E SEMI-

\section{ACÚSTICOS.}

Nome:

Estudante da UNINCOR? ( ) Sim ( ) Não

Se SIM, qual o curso? Período:

É guitarrista? ( ) Sim ( )Não

Apresentamos a guitarra IMG_AV-1 feita sob a coordenação dos alunos Alexsander Vanzela e Leandro Trombini na luthieria Imagem do Som em Gouveia - MG.

\section{QUESTIONÁRIO PARA PESQUISA}

1 - O que achou do visual da guitarra?

( ) LINDA( ) BONITA ( ) NORMAL ( ) FEIA

2 - O shape lhe agradou? ( ) SIM ( ) NÃO

Se não, o que mudaria?

3 - O braço lhe agradou? ( )SIM （ ) NÃO

Se não, o que mudaria?

4 - Sobre o timbre do captador do braço o que achou?

( ) ÓTIMO ( ) BOM ( ) REGULAR ( ) RUIM

5 - Sobre o timbre do captador da ponte o que achou?

( ) ÓTIMO ( ) BOM ( ) REGULAR ( ) RUIM

6 - Sobre a ponte e a alavanca o que achou?

( ) ÓTIMO ( ) BOM ( ) REGULAR ( ) RUIM

7 - você compraria essa guitarra se ela estivesse a venda? ( ) SIM ( ) NÃO

\section{Autorização}

$\mathrm{Eu}$,

abaixo assinado, autorizo para os fins de Trabalho de

Conclusão de Curso os dados por mim fornecidos.

Três Corações, de setembro de 2011.

Assinatura:

\section{ANEXO B}

Gráficos originados da análise dos instrumentos

testados em estúdio
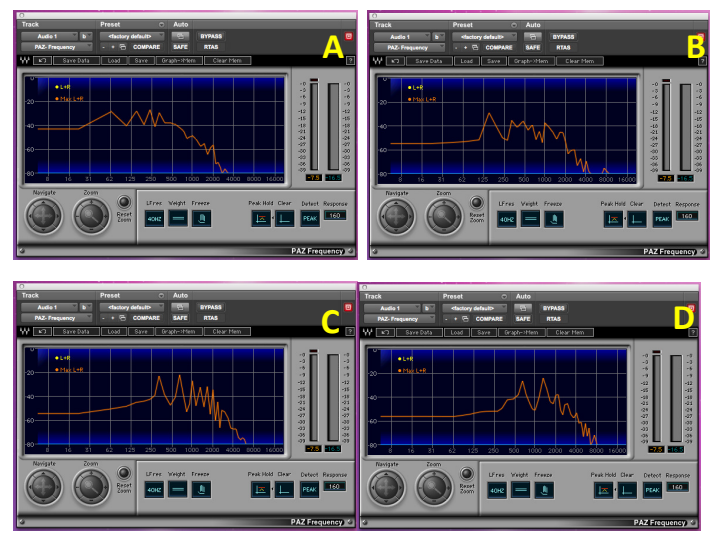

Figura 17 - Gráficos do captador do braço da guitarra AV-1. (A)E1, (B) E2, (C)E3 e (D)E4.

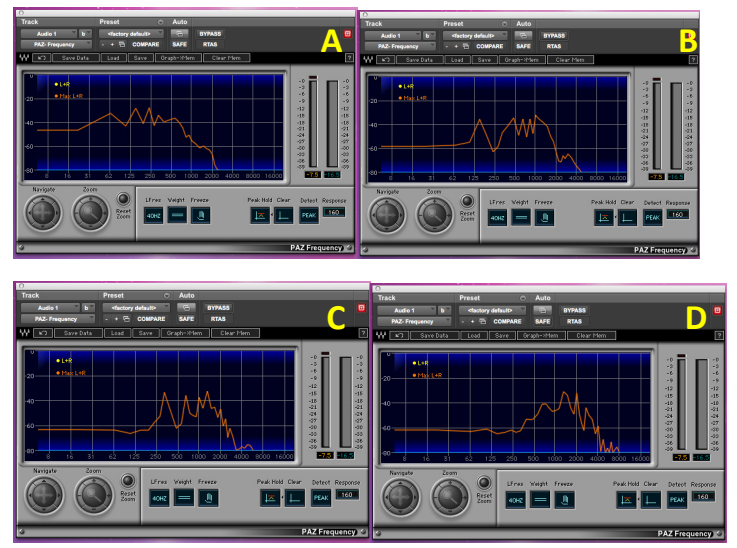

Figura 18 - Gráficos do captador da ponte da guitarra AV-1. (A)E1, (B) E2, (C)E3 e (D)E4.
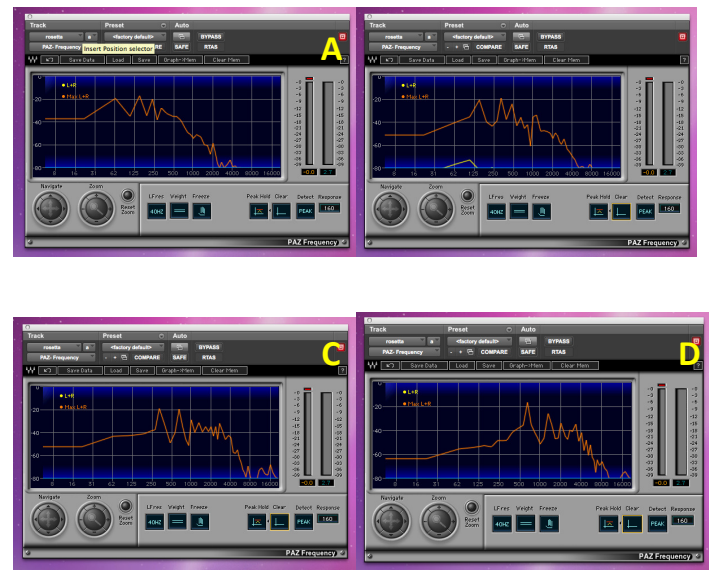

Figura 19 - Gráficos do captador do braço da guitarra Gibson. (A)E1, (B) E2, (C)E3 e (D)E4. 

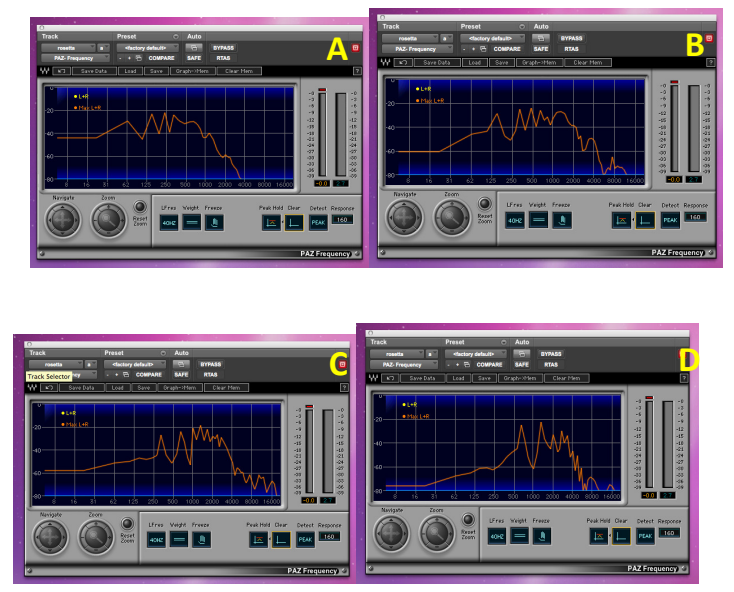

Figura 20 - Gráficos do captador da ponte da guitarra Gibson. (A)E1, (B) E2, (C)E3 e (D)E4.
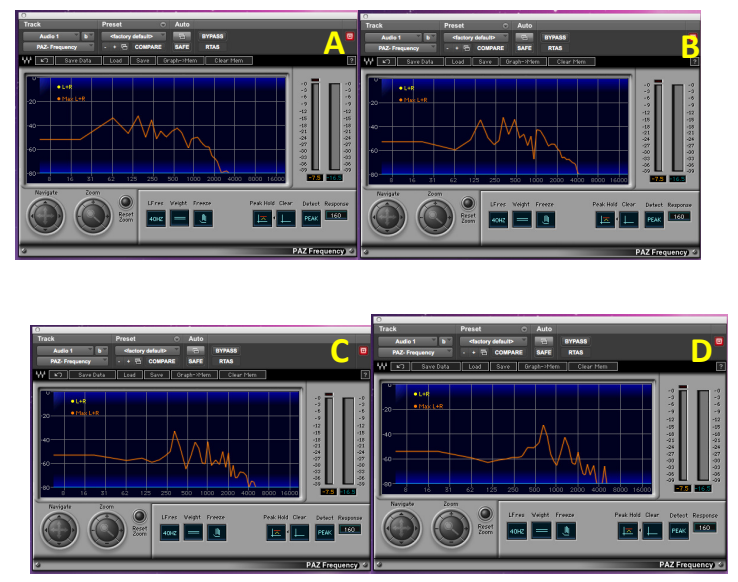

Figura 21 - Gráficos do captador do braço da guitarra Ibanez Roadstar. (A)E1, (B) E2, (C)E3 e (D)E4.
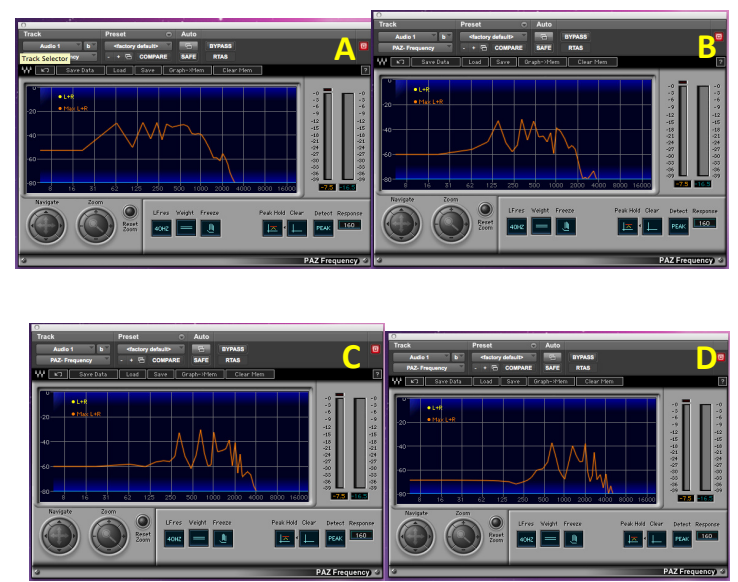

Figura 22 - Gráficos do captador da ponte da guitarra Ibanez Roadstar. (A)E1, (B) E2, (C)E3 e (D)E4.
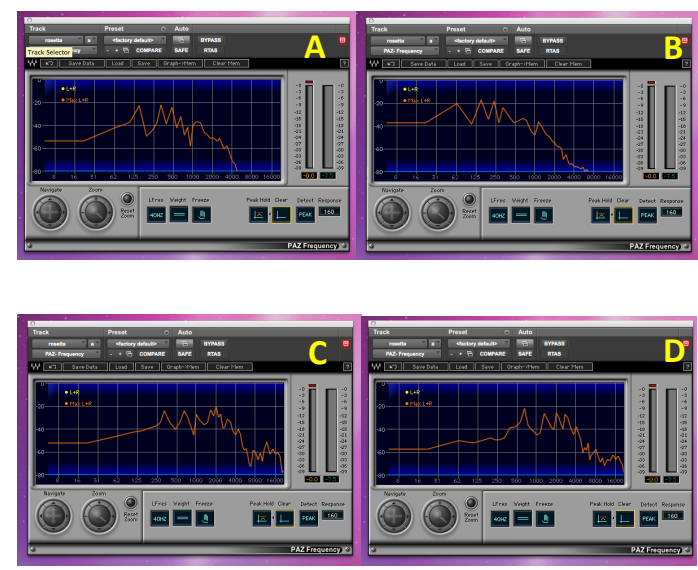

Figura 23 - Gráficos do captador do braço da guitarra Jackson KV1. (A)E1, (B) E2, (C)E3 e (D)E4.
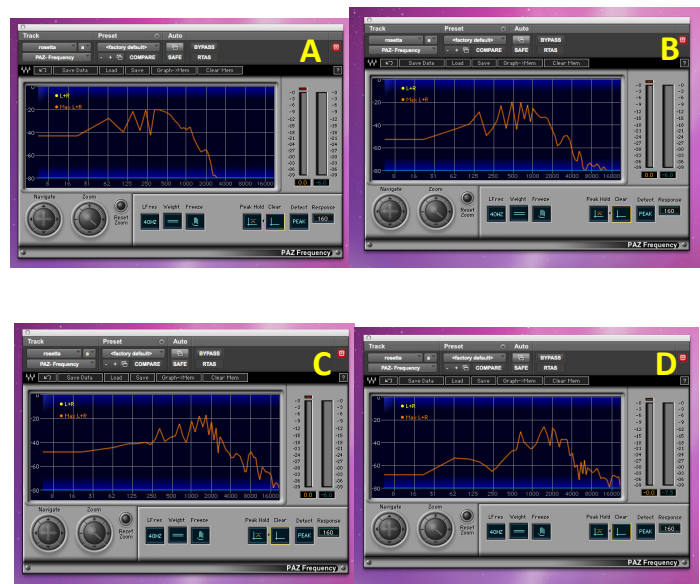

Figura 24 - Gráficos do captador da ponte da guitarra Jackson KV1. (A)E1, (B) E2, (C)E3 e (D)E4.
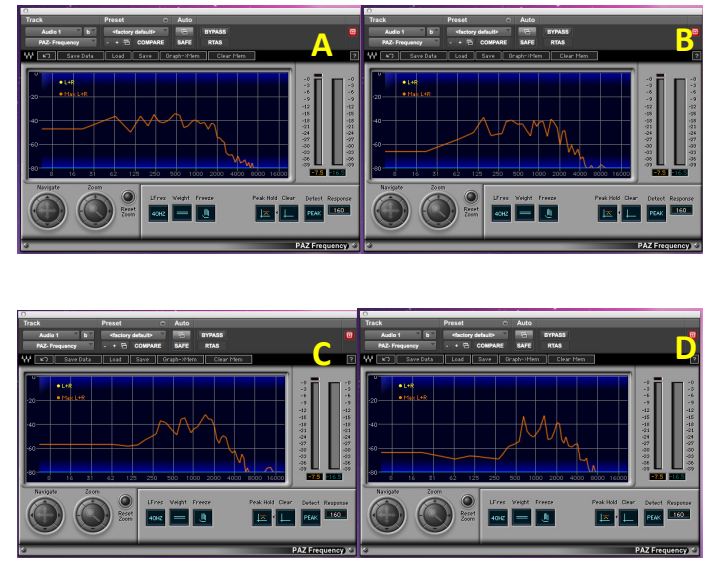

Figura 25 - Gráficos do captador do braço da guitarra Semi-acústica. (A)E1, (B) E2, (C)E3 e (D)E4. 

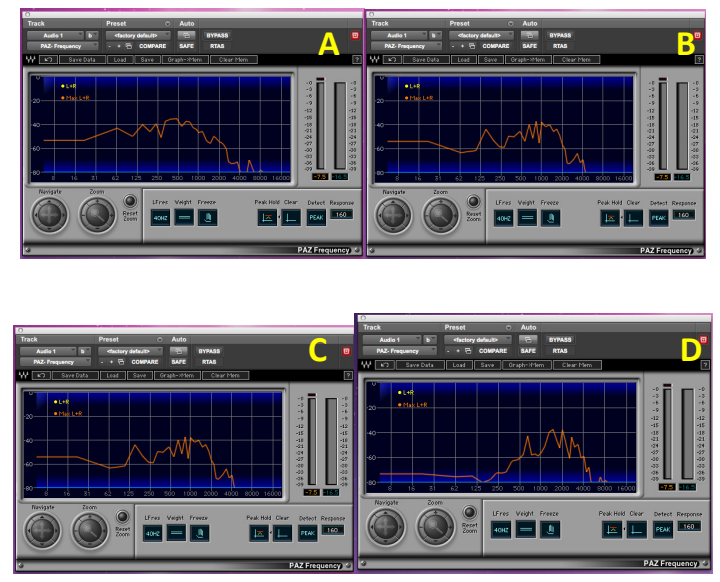

Figura 26 - Gráficos do captador da ponte da guitarra Semi-acústica. (A)E1, (B) E2, (C)E3 e (D)E4.

\section{REFERÊNCIAS BIBLIOGRÁFICAS}

FERNANDES, Gustavo de Amorim. Avaliação de madeiras brasileiras para utilização em guitarras elétricas. 2004. 39 p. Trabalho de Conclusão do Curso de Engenharia Florestal - Universidade de Brasília, Brasília.

ONO, Teruaki \& OKUDA, Akira. Acoustic characteristics of guitars with a top board of carbon fiber-reinforced composites. Acoust. Sci \& Tech, Japão, 28 (6), 442 - 443, Junho de 2007.

SOUZA, Neigmar. Guitarra elétrica: um ícone na cultura pop do século XX. Revista Vernáculo, Paraná, n5, 33 - 45, 2002. 